77 VITAMIN D DEFICIENCY IS ASSOCIATED WITH DISABILITY IN MULTIPLE SCLEROSIS PATIENTS INDEPENDENTLY OF OXIDATIVE AND NITROSATIVE STRESS

'S Oliveira, ${ }^{2} \mathrm{D}$ Frizon Alfieri, ${ }^{3} \mathrm{~A}$ Simão*, ${ }^{1} \mathrm{~L}$ Mezzaroba, AP Kallaur', ${ }^{2} \mathrm{~T}$ Flauzino, I Dichi', ${ }^{1} \mathrm{M}$ Alysson B Lozovoy, ${ }^{5} \mathrm{~B}$ Sardinha Sabino, ${ }^{6} \mathrm{~K}$ Panichi Zanin Ferreira, ${ }^{6} \mathrm{~W}$ LCJ Pereira, ${ }^{7}$ DR Kaimen-Maciel, ${ }^{8}$ EM Vissoci Reiche. ${ }^{1}$ State University of Londrina, Department of Pathology-Clinical Analysis and Toxicology- Health Sciences Centre, Londrina, Brazil; ${ }^{2}$ State University of Londrina, Postgraduate Program- Health Sciences Centre, Londrina, Brazil; ${ }^{3}$ Universidade Estadual de Londrina, Department of Pathology, Clinical Analysis and Toxicology, Londrina, Brazil; ${ }^{4}$ State University of Londrina, Department of Clinical MedicineHealth Sciences Centre, Londrina, Brazil; ${ }^{5}$ State University of Londrina, Pharmacy SchoolHealth Sciences Center- State University of Londrina, Londrina, Brazil; ${ }^{6}$ State University of Londrina, Postgraduate Program- Health Sciences Center- State University of Londrina, Londrina, Brazil; ' 5 State University of Londrina, 3Department of Clinical Medicine- Health Sciences Center- State University of Londrina- Londrina- Paraná- Brazil-, Londrina, Brazil; ${ }^{8}$ State University of Londrina, Department of Pathology- Clinical Analysis and ToxicologyHealth Sciences Center- State University of Londrina- Londrina- Paraná- Brazil, Londrina, Brazil

\subsection{6/lupus-2017-000215.77}

Background and aims The aim of this study was to assess vitamin D status in patients with multiple sclerosis (MS) and to evaluate whether it was associated with oxidative and nitrosative stress (O and NS) markers and disability.

Methods This study included 137 patients with MS and 218 healthy controls. The markers evaluated were serum levels of 25-hydroxyvitamin D, lipid hydroperoxides, advanced oxidation protein products (AOPP), nitric oxide metabolites (NOx), and total radical-trapping antioxidant parameter TRAP/UA.

Results MS patients presented higher age $(\mathrm{p}<0.0001)$, and lower 25(OH)D $(\mathrm{p}=0.002), \mathrm{NOx}$, and TRAP/UA $(<0.0001)$ than controls. When the age was used as an additional explanatory variable in binary logistic regression analyses, 25 $(\mathrm{OH}) \mathrm{D}, \mathrm{NOx}$, and TRAP/UA remained significant $(\mathrm{p}=0.016$, $\mathrm{p}<0.0001$, and $\mathrm{p}=0.002$, respectively). Patients with $25(\mathrm{OH})$ $\mathrm{D}<20 \mathrm{ng} / \mathrm{mL}$ showed higher EDSS $(\mathrm{p}=0.016)$ and lower AOPP $(p=0.046)$ than those with $25(\mathrm{OH}) \mathrm{D} \geq 20 \mathrm{ng} / \mathrm{mL}$. After the binary logistic regression analyses, EDSS remained significantly associated with vitamin $\mathrm{D}$ deficiency. We showed that lower levels of $25(\mathrm{OH})$ were associated with higher EDSS independently of variables such as $\mathrm{O}$ and NS (AOPP and NOx), age, sex, body mass index, ethnicity, disease duration, MS therapy, use of interferon beta, and clinical forms of MS (odds ratio: 1.380, 95\% confidence interval 1.030-1.843, $\mathrm{p}=0.031)$. Moreover, the study showed an association between serum levels of $25(\mathrm{OH}) \mathrm{D}$ and EDSS $\left(\mathrm{r}^{2}=0.115, \mathrm{p}=0.002\right)$, demonstrating that $25(\mathrm{OH}) \mathrm{D}$ may contributed with $11.5 \%$ of increase in EDSS.

Conclusions Our results suggest that vitamin D deficiency may be considered one of the predictors of the disability in MS patients, independently of their redox status.
New therapies and therapeutic targets - SLE

\section{TRANSMEMBRANE ACTIVATOR AND CALCIUM- MODULATING CYCLOPHILIN LIGAND INTERACTOR AS A PROMISING NOVEL TARGETED THERAPY FOR SYSTEMIC LUPUS ERYTHEMATOSUS}

${ }^{1}$ FF Alkaff, ${ }^{1}$ RA Nugraha, ${ }^{1} \mathrm{M}$ Jnatan, ${ }^{2} \mathrm{~A}$ Awalia. 'Airlangga University, Faculty Of Medicine, Surabaya, Indonesia; ${ }^{2}$ Airlangga University, Rheumatology Division- Intrnal Medicine Department, Surabaya, Indonesia

\subsection{6/lupus-2017-000215.78}

Background and aims Nowadays, the definitive therapy to cure SLE has not been found yet. The newest drug available, Belimumab and Rituximab, cannot cure all kind of SLE manifestation. Moreover, both of those drugs also decrease the number of $\mathrm{B}$ cell in the body. Transmembrane Activator and CalciumModulating Cyclophillin Ligand Interactor (TACI) is an immunology based target therapy that expected to give a better result in induct remission without decreasing the number of $\mathrm{B}$ cell.

Aims Analyse the possibility of TACI inhibition as a targeted therapy for SLE, in order to accelerate the remission period with less side effects.

Methods We look up for scienctif article comprehensively in Medline, Science Direct, PubMed, and Cochrane Database. We found 10 article based on bibliography and keywords from the database.

Results TACI expression is elevated in B cells from patients with SLE. Inhibition of TACI cause an inhibition to B cell differentiation, and also decrease the amount of plasma cell, which cause a decreasing quantity of autoantibody which circulate in the blood. Inhibition of TACI will fully protects the animals against autoantibody production, without having any impact on B cell survival. This inhibition also delays the onset of proteinuria, albuminuria, basement membrane thickening, tubulointerstitial fibrosis, and glomerulosclerotic disease. It also inhibits only the $\mathrm{T}$-cell independent responses and T-cell dependent (IgA), but it will maintain T-cell dependent protective B-cell functions.

Conclusions Inhibition of TACI may give better outcome compared to current therapy. However, the study for now is only limited in mouse.

\section{EFFECTS OF AN ORAL SELECTIVE SPHINGOSINE 1- PHOSPHATE RECEPTOR MODULATOR IN A MOUSE MODEL OF SLE}

${ }^{1} K R$ Taylor, ${ }^{1} M$ Steinberg, ${ }^{1} R J$ Peach, ${ }^{2} H$ Rosen, ${ }^{1} G J$ Opiteck, ${ }^{1} M$ Stokes, ${ }^{1} B R$ Clemons, FL Scott. ${ }^{1}$ 'Receptos- Inc., Research, San Diego- California, USA; ${ }^{2}$ Scripps Research Institute, The Rosen Laboratory, La Jolla- California, USA

10.1136/lupus-2017-000215.79 
Background and aims Ozanimod (RPC1063) is a specific and potent small molecule modulator of $\mathrm{S}_{1} \mathrm{P}_{1}, 5 \mathrm{R}$ that has shown therapeutic benefit in clinical trials of relapsing multiple sclerosis and ulcerative colitis. Its metabolite, RP-101075, shares ozanimod's specificity profile at the S1P receptor family in vitro, and its pharmacokinetic (PK) and pharmacodynamic profile in vivo.

Methods The $(\mathrm{NZB} \times \mathrm{NZW}) \mathrm{F} 1$ model was used in therapeutic dosing mode to assess the benefit of an $\mathrm{S}_{1} \mathrm{P}_{1,5 \mathrm{R}}$ modulator in systemic lupus erythematosus (SLE), compared to cyclophosphamide.

Results As predicted for an $\mathrm{S}_{1} \mathrm{P}_{1,5 \mathrm{R}}$ modulator, treatment with 0.3, 1 and $3 \mathrm{mg} / \mathrm{kg} \mathrm{RP}-101075$ resulted in a dose-dependent reduction in circulating $\mathrm{T}$ and $\mathrm{B}$ cells, achieving 62\%99\% decrease across all doses tested. Compared to vehicle treated animals, $3 \mathrm{mg} / \mathrm{kg} \mathrm{RP}-101075$ reduced proteinuria over the duration of the study (34 \pm 5 vs $18 \pm 1 \quad \mathrm{U}^{*}$ week; $\mathrm{p}<0.0001)$, and blood urea nitrogen $(36 \pm 5$ vs $21 \pm 3 \mathrm{mg} / \mathrm{dL}$; $\mathrm{p}<0.0001)$. Additionally, RP-101075 reduced kidney disease in a dose dependent manner, as quantified by histological assessment of mesangial expansion, endo- and exo-capillary proliferation, interstitial infiltrates and fibrosis, glomerular deposits and tubular atrophy. In addition, RP-101075 significantly reduced expression of fibrotic and immune genes in the kidneys, with minimal effect on IFN-inducible genes. Of particular note, RP-101075 lowered the number of plasmacytoid dendritic cells, a major source of IFN $\alpha$ in lupus patients, and all $\mathrm{B}$ and $\mathrm{T}$ cell subsets in the spleen.

Conclusions Given that RP-101075 shares the pharmacokinetic profile of ozanimod and reduces circulating lymphocytes similarly, ozanimod warrants clinical evaluation as a potential treatment for SLE.

\section{IS SPLENECTOMY A SAFE AND EFFECTIVE THERAPEUTIC OPTION IN SYSTEMIC LUPUS ERYTHEMATOSUS? A SINGLE-CENTRE STUDY}

A Barrera-Vargas*, S Morales-Padilla, R Vázquez-Rodríguez, R Reyna-de-la Garza, J Merayo-Chalico, J Alcocer-Varela, D Gómez-Martín. Instituto Nacional de Ciencias Médicas y Nutrición Salvador Zubirán, Immunology and Rheumatology, Mexico City, Mexico

\subsection{6/lupus-2017-000215.80}

Background and aims Thrombocytopenia is a relatively common feature in systemic lupus erythematosus (SLE) patients, although severe thrombocytopenia is rare. Splenectomy is considered an acceptable treatment option for refractory thrombocytopenia in different haematological conditions. However, its role in SLE has been controversial, due to potential surgical complications and to its possible association with SLE flares. The aim of this study was to determine safety and efficacy of splenectomy in a cohort of SLE patients.

Methods We included all patients with SLE who fulfilled $\geq 4$ ACR criteria, and underwent splenectomy between 2000 and 2015 in a tertiary care centre in Mexico City. Patients with other rheumatic diseases (except for anti-phospholipid syndrome) were excluded. We recorded demographic, clinical and serological characteristics at the time of surgery and during follow-up.

Results Thirty-six patients were included, 91.7\% were women and mean age was $33.31 \pm 12.95$. Refractory thrombocytopenia was the surgical indication in 28 patients $(77.7 \%)$. Laparoscopic splenectomy was performed in $80.6 \%$ of cases. Two patients had surgical complications (intra-abdominal sepsis and pancreatic fistula). There were no deaths directly associated with the procedure. Among patients with thrombocytopenia, $85.7 \%$ achieved complete remission, in a mean period of 1.65 \pm 3.13 months. Cumulative prednisone dose in the year after the surgery was lower than the year before $(8.7 \pm 5.8$ vs 4.2 \pm 3.2 grams, $\mathrm{p}<0.01)$. Mean SLEDAI score at baseline was $3.53 \pm 2.9$, and it decreased at 3 and 6 months $(1.15 \pm 2.07$ and $1.21 \pm 2.38, \mathrm{p}<0.01$, respectively) during follow-up.

Conclusions Splenectomy is a safe procedure in SLE patients, and it represents an effective therapeutic option for refractory thrombocytopenia.

\section{OUTCOMES OF MULTI-TARGET THERAPY USING MYCOPHENOLATE MOFETIL AND TACROLIMUS FOR REFRACTORY LUPUS NEPHRITIS}

CB Choi*, S Won, HH Kwon, SW Nam, SC Bae. Hanyang University Hospital for Rheumatic Diseases, Rheumatology, Seoul, Republic of Korea

\subsection{6/lupus-2017-000215.81}

Background and aims Outcomes of systemic lupus erythematosus (SLE) has significantly improved over the years. However, it can still be unfavourable when there is major organ involvement such as lupus nephritis and standard therapies fail. Outcomes of multi-target therapy using mycophenolate mofetil (MMF) and tacrolimus in SLE patients who were refractory to standard therapy was assessed.

Methods Retrospective analysis was done in patients with biopsy-confirmed lupus nephritis class III or IV who failed to achieve complete response with standard induction therapy for 24 weeks and switched to multi-target combination therapy with MMF and tacrolimus. Outcomes including renal response, urine protein/creatinine ratio (UPCR), glomerular filtration rate (GFR), serum albumin, and complements were assessed at 24 weeks.

Results A total of 20 patients, with mean age of $27.9 \pm 8.2$ years and $82.8 \%$ female, who initiated MMF and tacrolimus combination therapy were included. At 24 weeks, $25.9 \%$ showed complete response and $37.0 \%$ showed partial response. When all patients were compared, the mean UPCR increased from $3.06 \pm 3.00$ at baseline to $3.21 \pm 4.23$ at 24 weeks and GFR declined from $96.55 \pm 37.07 \mathrm{~mL} / \mathrm{min} / 1.73 \mathrm{~m}^{2}$ to $92.00 \pm 41.12 \mathrm{~mL} / \mathrm{min} / 1.73 \mathrm{~m}^{2}$. But in subgroup comparison, UPCR decreased from $1.82 \pm 0.86$ to $1.39 \pm 0.85$ in patients who had shown partial response to standard induction therapy and increased from $5.61 \pm 2.93$ to $8.62 \pm 4.11$ in no response patients.

Conclusions Multi-target therapy combining MMF and tacrolimus can be considered in patients who had partial response to standard induction therapy in patients with lupus nephritis.

\section{ETHANOL PREVENTS DAMAGE OF SKIN, KIDNEY AND JOINT IN LUPUS-PRONE MICE BY REGULATING LIPID RAFTS}

${ }^{1} \mathrm{H}$ Dou, ${ }^{2} \mathrm{~L}$ Liu, ${ }^{1,2} \mathrm{GM}$ Deng*. ${ }^{1}$ Nanjing Medical University, Key Laboratory of Antibody Techniques of Ministry of Health, Nanjing, China; ${ }^{2}$ Harvard Medical School, Beth Israel Deaconess Medical Centre, Boston, USA

\subsection{6/lupus-2017-000215.82}

Background and aims Ethanol has been elaborated to have a beneficial effect on destructive arthritis. Nevertheless, the 